Arkivoc

Free to Authors and Readers
A Platinum Open Access Journal for Organic Chemistry

Paper

DOAJ Seal
Arkivoc 2021, part vi, 13-25

\title{
Catechol-based macrocyclic aromatic ether-sulfones: Synthesis, characterization and ring-opening polymerization
}

\author{
Fabio Aricò*a and Howard M. Colquhoun*b \\ ${ }^{a}$ Department of Environmental Sciences, Informatics and Statistics, Ca' Foscari University, \\ Via Torino 155, 30172 Venice, Italy \\ ${ }^{b}$ Department of Chemistry, University of Reading, Whiteknights, Reading, RG6 6AD, UK \\ Email: fabio.arico@unive.it; h.m.colquhoun@rdg.ac.uk
}

Dedicated to Professor Philip Hodge, recognising his contributions to polymers in synthesis over 45 years

Received 11-20-2020

Accepted 01-27-2021

Published on line 01-30-2021

\section{Abstract}

Cyclocondensation between 4,4'-bis(4"-chlorobenzenesulfonyl)biphenyl and catechol, with subsequent chromatographic separation of the reaction products, led to the isolation of four novel ether-sulfone macrocycles (cyclic dimer, -trimer, -tetramer and -pentamer). Similarly, cyclocondensation of catechol with a novel seven-ring diketone/disulfone monomer allowed the isolation of the two new aromatic ether-ketonesulfone macrocycles, a cyclic monomer and a cyclic dimer. Transannular shielding and deshielding effects in the cyclic monomer produce substantial chemical shift differences for chemically equivalent protons in the ${ }^{1} \mathrm{H}$ NMR spectra of the cyclic monomer and-dimer. Fluoride-initiated ring-opening polymerization of the ethersulfone cyclic trimer affords a novel, high-molecular weight poly(ether-sulfone).

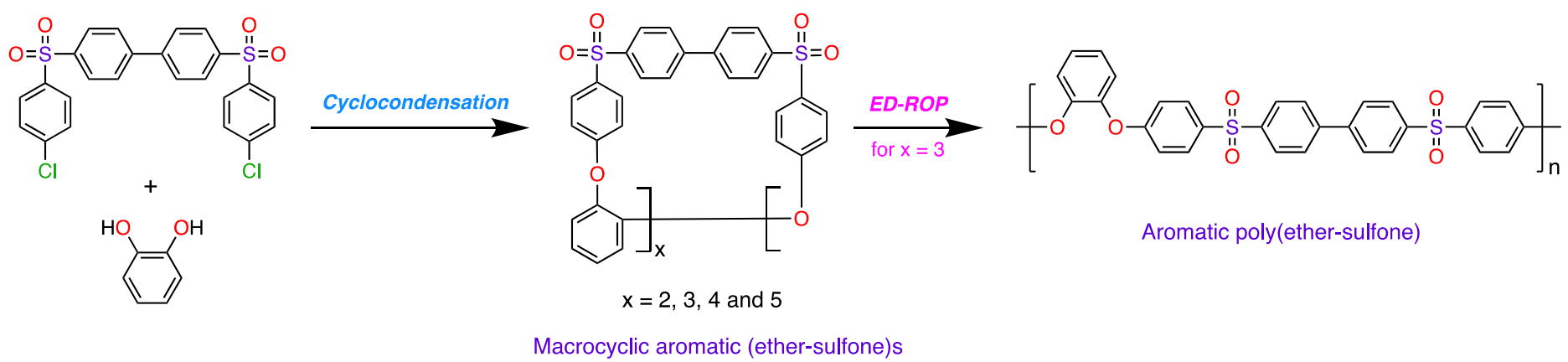

Keywords: Cyclocondensation, macrocycles, ring-opening polymerization, aromatic poly(ether-sulfone)s. 


\section{Introduction}

The molecular structures of high-temperature engineering thermoplastics generally comprise linear chains of aromatic rings, linked together by thermo-oxidatively stable units such as direct arene-arene bonds, ether, ketone, sulfone, amide or imide groups. ${ }^{1,2}$ Aromatic poly(ether-sulfone)s, exemplified in Chart 1, comprise an industrially-significant class of such polymers: these materials may in principle be accessed either by electrophilic chemistry (polysulfonylation) ${ }^{3}$ or by activated nucleophilic substitution (polyetherification) ${ }^{4}$ at the aromatic rings. In practice the nucleophilic route, involving the displacement of sulfone-activated chloride by phenoxide ion, has generally proved more selective and versatile both in the laboratory and in commercial production. ${ }^{5,6} \mathrm{~A}$ more recently-discovered approach to polymers of this type involves the ring-opening polymerization (ROP) of macrocyclic aromatic (ether-sulfone)s. 7,8 Macrocyclic oligomers are present in small, equilibrium quantities (typically 1-3 wt\%) in many linear step-growth polymers, including the poly(ethersulfone)s, ${ }^{9,10,11}$ but they may also be obtained in high yield either by cyclo-condensation of monomers under pseudo-high-dilution conditions, ${ }^{12-16}$ or by ring-closing depolymerization of high molecular weight (MW) polymer at low concentration in solution., ${ }^{77,18}$
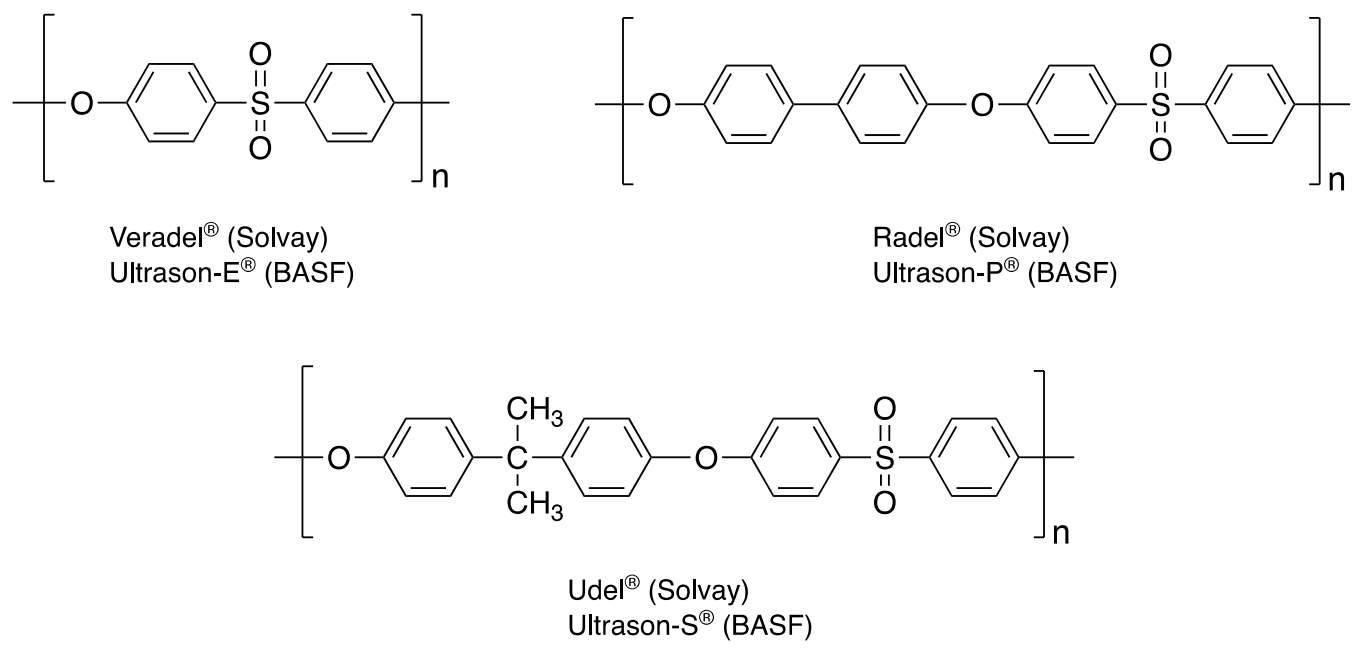

Chart 1. Industrially-significant aromatic poly(ether sulfone)s, showing current (2020) trade-names and manufacturers.

Both ring-opening polymerization and ring-closing depolymerization exploit the ring-chain equilibrium that can be established (generally in the presence of a suitable catalyst) between a high molecular weight, step-growth linear polymer and a homologous family of macrocyclic oligomers. ${ }^{19-21}$ An important feature of such a system is that at high concentrations the equilibrium lies heavily in the direction of polymer, whilst at low concentrations it shifts to favor macrocylic oligomers. For example, under very concentrated or even solvent-free reaction conditions an equilibrated system would typically contain ca. $98 \mathrm{wt} \%$ polymer and only ca. $2 \%$ macrocycles, whilst under dilute conditions (say $1 \mathrm{wt} \%$ of solutes) the system can easily comprise $>90 \%$ of macrocycles, and may even consist exclusively of these. ${ }^{22}$ Thus, if a neat macrocyclic oligomer, or a mixture of homologous macrocylic oligomers, is allowed to undergo reversible cleavage, for example at high temperature in the presence of a catalyst, then ring-opening polymerization will occur. Such polymerizations involve only a shuffling of the linkages between repeat units and have several potentially valuable features. For example, no volatiles or other by-products are generated and, as the macrocycles are generally large 
enough to be strainless, little or no heat is evolved. The latter process may therefore be described as an entropy-driven ring-opening polymerization (ED-ROP). ${ }^{22}$ Conversely, when a dilute solution of high molar mass polymer is allowed to equilibrate by reversible chain-cleavage, then macrocyclic oligomers are formed in high yield by ring-closing depolymerization (RCDP). ${ }^{7,17,18}$ It has been proposed that a combination of RCDP and EDROP could form the basis of a technique for recycling high-value step-growth polymers, and such processes have been investigated for several different polymers of this type, ${ }^{18,23-25}$ including the poly(ether-sulfones). ${ }^{24}$

The vast majority of industrially-significant aromatic thermoplastics are based on 1,4-linked phenylene units, ${ }^{1,2}$ although 1,3-linkages are found in a number of cases, as for example in the high-temperature polyamide poly(1,3-phenylene isophthalamide), ${ }^{27}$ trademarked as Nomex ${ }^{\circledR}$. Relatively little work has been reported on analogous systems based on the 1,2-phenylene unit, although a benzene-1,2-dioxy-based analogue of the all-para engineering poly(ether-ketone) known as PEEK has been obtained by Hodge and coworkers from polycondensation of benzene-1,2-diol (catechol) with 4,4'-difluorobenzophenone, and an equilibrium between this polymer and its homologous family of macrocylic oligomers (Chart 2; a) was shown to be established at high temperature in the presence of fluoride ions. ${ }^{28}$ More recently, o-PEEK macrocycles have been employed to fabricate carbon fibre composites via ring opening polymerization reactions. ${ }^{29}$ The present study might also lead the way to novel in-situ fabrication of high performance thermoplastic composites.

Other investigations on polymers containing catechol as co-monomer include work on poly(esterimide)s, PEls, synthesized by polycondensation of $\mathrm{N}$-(4-carboxyphenyl) trimellitimide or $\mathrm{N}$-(3carboxyphenyl)trimellitimide with catechols or 5-methylresorcinol (Chart $2 ;$ b). ${ }^{30}$ It is also noteworthy that catechol residues are present in the highly complex aromatic backbone of the biopolymer lignin, which is attracting increasing interest as a component of bio-thermoplastics as potential alternatives to petroleumderived materials. ${ }^{31}$

(a)

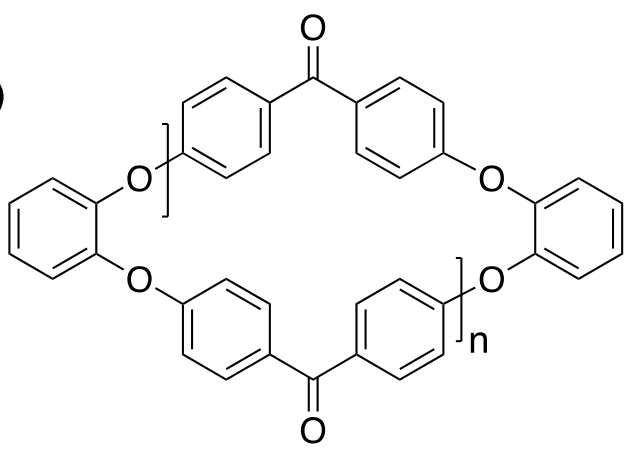

(b)

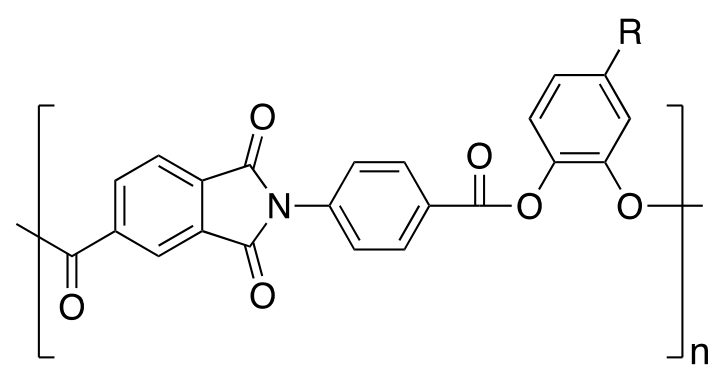

Chart 2. (a) Catechol-based macrocyclic aromatic ether-ketones ${ }^{28,29}$; (b) Catechol-based aromatic poly(esterimide)s $(\mathrm{R}=\mathrm{H}$, Me, or $t-\mathrm{Bu}) .^{30}$

In the present work, we report the synthesis, characterization, and entropy-driven ring-opening polymerization of a novel series of macrocyclic aromatic (ether-sulfone)s derived from catechol by nucleophilic cyclo-condensation with extended aromatic dichloro-compounds, activated towards nucleophilic (SNAr) substitution by the presence of sulfone groups para to the chloro-substituents. 


\section{Results and Discussion}

Cyclo-condensation of catechol with 4,4'-bis(4"-chlorobenzenesulfonyl)biphenyl ${ }^{32}$ (1) was achieved under pseudo-high dilution conditions by slow, continuous addition of a concentrated solution of 1 and catechol in dimethylacetamide (DMAc) to a suspension of potassium carbonate in DMAc/toluene at $160{ }^{\circ} \mathrm{C}$, affording a mixture of macrocyclic aromatic (ether-sulfone)s (Scheme 1).

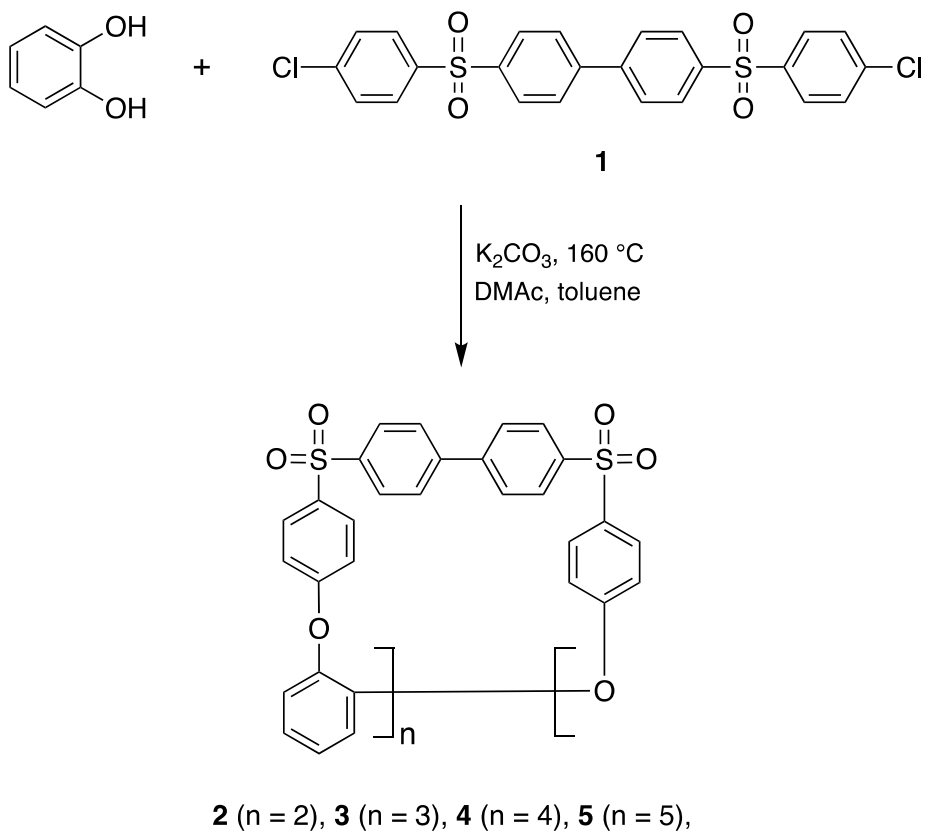

Scheme 1. Synthesis of cyclic oligomers 2, 3, 4 and 5 under pseudo-high dilution conditions.

Fractionation of the resulting mixture of cyclic oligomers by gradient elution chromatography afforded a series of macrocycles as pure compounds including the cyclo-dimer 2 (7.8\%), -trimer 3 (3.4\%), -tetramer 4 (2.0\%) and -pentamer 5 (1.5\%). The thermal characteristics and solubility properties of the four isolated macrocycles are summarized in Table 1 . The cyclic oligomers with an even number of repeat units (dimer and tetramer) are crystalline, high-melting, and soluble only in strongly acidic solvent mixtures (e.g. chloroform/trifluoroacetic acid), while the cyclic trimer and pentamer are essentially amorphous compounds with good solubility in simple chlorinated solvents. Very similar odd/even behaviour has previously been

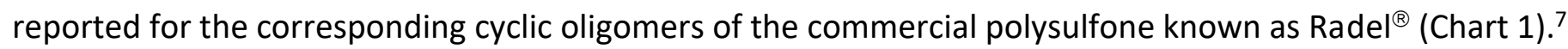

Table 1. Characterization of ether-sulfone cyclic oligomers 2, 3, 4 and 5 (Scheme 1)

\begin{tabular}{lllll}
\hline & $\mathbf{2}$ & $\mathbf{3}$ & $\mathbf{4}$ & $\mathbf{5}$ \\
\hline Yield $(\%)$ & 7.8 & 3.4 & 2.0 & 1.5 \\
${ }^{a} \mathrm{~T}_{\mathrm{m}}\left({ }^{\circ} \mathrm{C}\right)$ & 514 & $n d$ & 425 & nd \\
${ }^{b} \mathrm{~T}_{\mathrm{c}}\left({ }^{\circ} \mathrm{C}\right)$ & 280 & $n d$ & $n d$ & nd \\
${ }^{c} \mathrm{~T}_{\mathrm{g}}\left({ }^{\circ} \mathrm{C}\right)$ & $n d$ & 205 & 206 & 205 \\
Solvent & $\mathrm{CHCl}_{3} / \mathrm{TFA}^{d}$ & $\mathrm{CHCl}_{3}$ & $\mathrm{CHCl}_{3} / \mathrm{TFA}^{d}$ & $\mathrm{CHCl}_{3}$ \\
\hline
\end{tabular}

${ }^{a} \mathrm{MPt}$ (on heating); ${ }^{b}$ Crystallization temperature (on cooling); ${ }^{c}$ Glass transition (onset); ${ }^{d} 5: 1 \mathrm{v} / \mathrm{v} ;$ nd = none detected 
The ${ }^{1} \mathrm{H}$ NMR spectra of macrocycles 2, 3, 4 and 5 are very similar, with only small chemical shift differences as a function of ring size as reported in the Supplementary Material (SM). The ${ }^{1} \mathrm{H}$ NMR spectrum of cyclic trimer $\mathbf{3}$ is shown in Figure 1. The symmetrical pair of multiplets at 7.25 and 7.38 ppm is characteristic of the catechol residue, and the highest field doublet, at $6.87 \mathrm{ppm}$, is assigned to the protons ortho to the ether linkage and meta to sulfone. Detailed assignments of all ${ }^{1} \mathrm{H}$ NMR spectra are given in the Experimental Section and the SM.

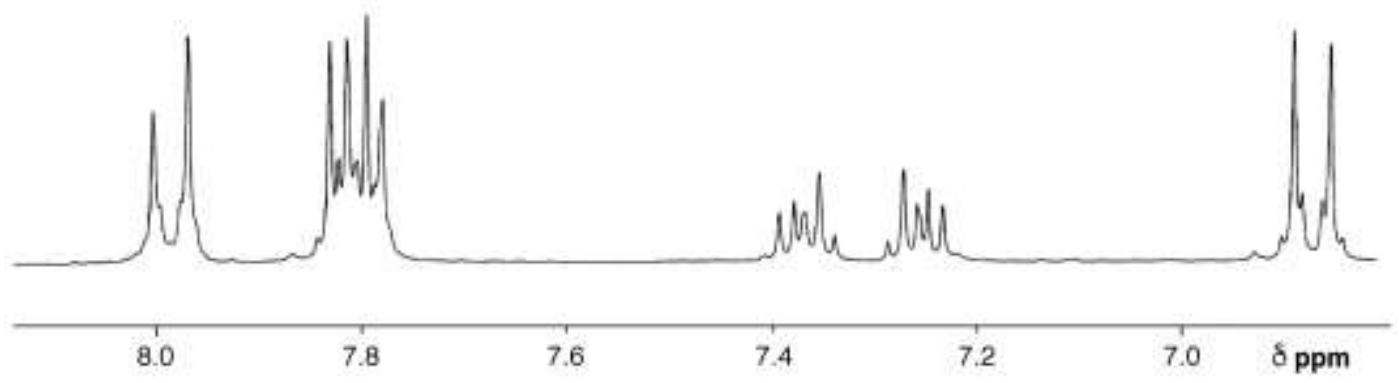

Figure 1. ${ }^{1} \mathrm{H} N M R$ spectrum $\left(250 \mathrm{MHz}, \mathrm{CD}_{2} \mathrm{Cl}_{2} / \mathrm{CH}_{3} \mathrm{SO}_{3} \mathrm{H}, 4 / 1 \mathrm{v} / \mathrm{v}\right)$ of cyclic trimer 3.

Each isolated macrocycle was identified by MALDI-TOF mass spectroscopy. The mass spectrum of the cyclic pentamer 5, for example, showed only a strong molecular ion at $\mathrm{m} / \mathrm{z} 2725$, representing the sodium adduct $[\mathrm{M}+\mathrm{Na}]^{+}$( $\mathrm{m} / z$ calc. 2726.0). Analogous mass spectra for macrocycles $\mathbf{2}, \mathbf{3}$ and $\mathbf{4}$ are given in the SM.

Following the development of a successful cyclo-condensation procedure for aromatic (ether-sulfone)s from catechol and the four-ring dihalide 1, we next investigated an analogous reaction between catechol and the seven-ring diketone/disulfone monomer $\mathbf{7}$, synthesized by a two-stage route as shown in Scheme 2.

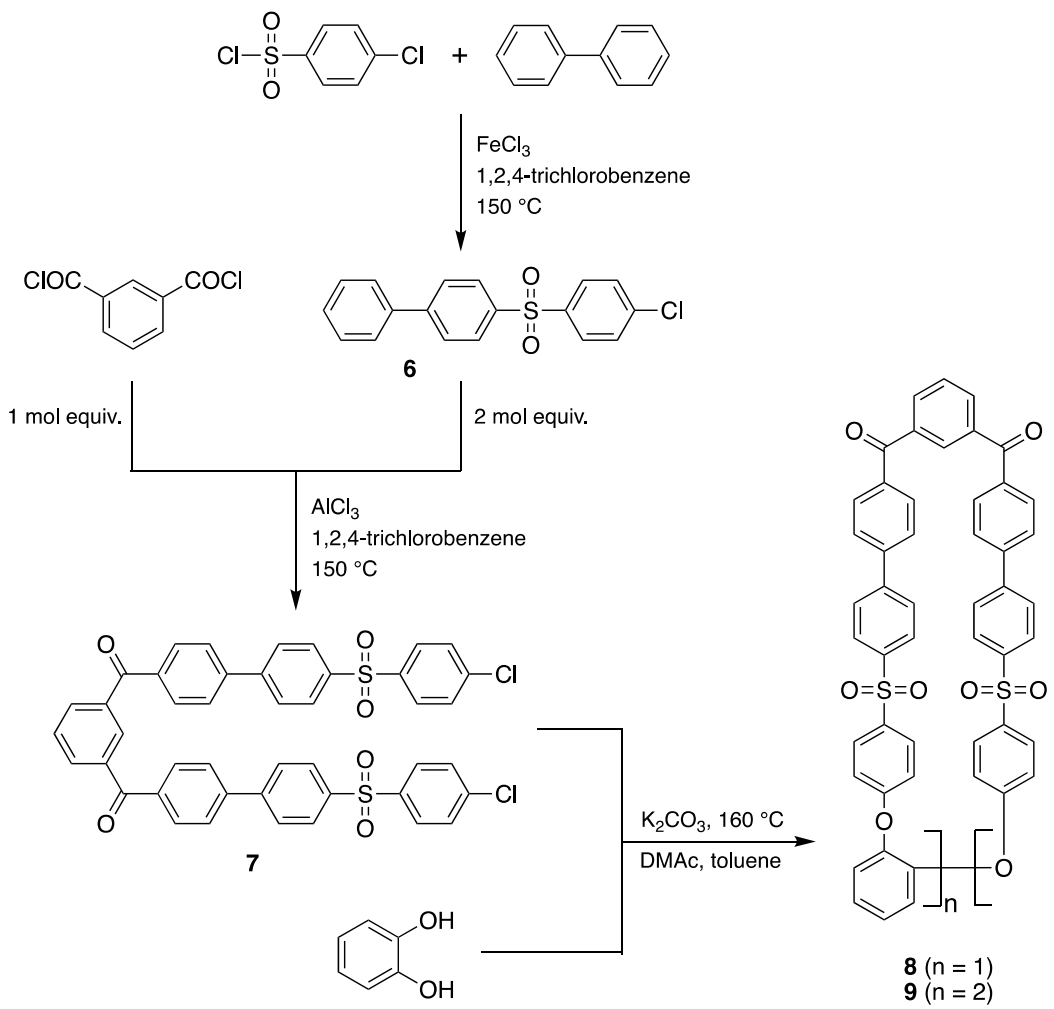

Scheme 2. Synthesis of monomer $\mathbf{7}$ and cyclic oligomers 8 and $\mathbf{9 .}$ 
The intermediate 4-(4'-chlorobenzenesulphonyl)biphenyl, 6, was obtained in 50\% yield from a FriedelCrafts reaction between biphenyl and 4-chlorobenzenesulphonyl chloride using anhydrous ferric chloride as catalyst. ${ }^{4}$ Subsequent reaction of 6 with isophthaloyl chloride afforded the seven-ring monomer 7 in $42 \%$ yield after recrystallization from DMF (Scheme 2). Its DSC thermogram showed a sharp melting peak at $284{ }^{\circ} \mathrm{C}$. The ${ }^{1} \mathrm{H}$ NMR spectrum observed was fairly complex (see ESI) but was fully consistent with the proposed structure, as indeed were the MALDI-TOF mass spectrum, COSY NMR analysis and ${ }^{13} \mathrm{C}$ NMR spectrum.

Condensation of monomer 7 with catechol under pseudo-high dilution conditions (Scheme 3) afforded a range of oligomeric molecules, and analysis of the crude product by MALDI-TOF MS demonstrated that these oligomers comprised exclusively macrocyclic species - specifically the cyclic monomer $\mathbf{8}$, cyclic dimer $\mathbf{9}$, and trace amounts of a cyclic trimer which was not subsequently isolated. The cyclic monomer (27\%) and cyclic dimer (2\%) were recovered as pure compounds by gradient elution chromatography. Their structures were confirmed by MALDI-TOF MS, and by ${ }^{1} \mathrm{H}$ and ${ }^{13} \mathrm{C}$ NMR spectroscopy (see Experimental Section and SM).

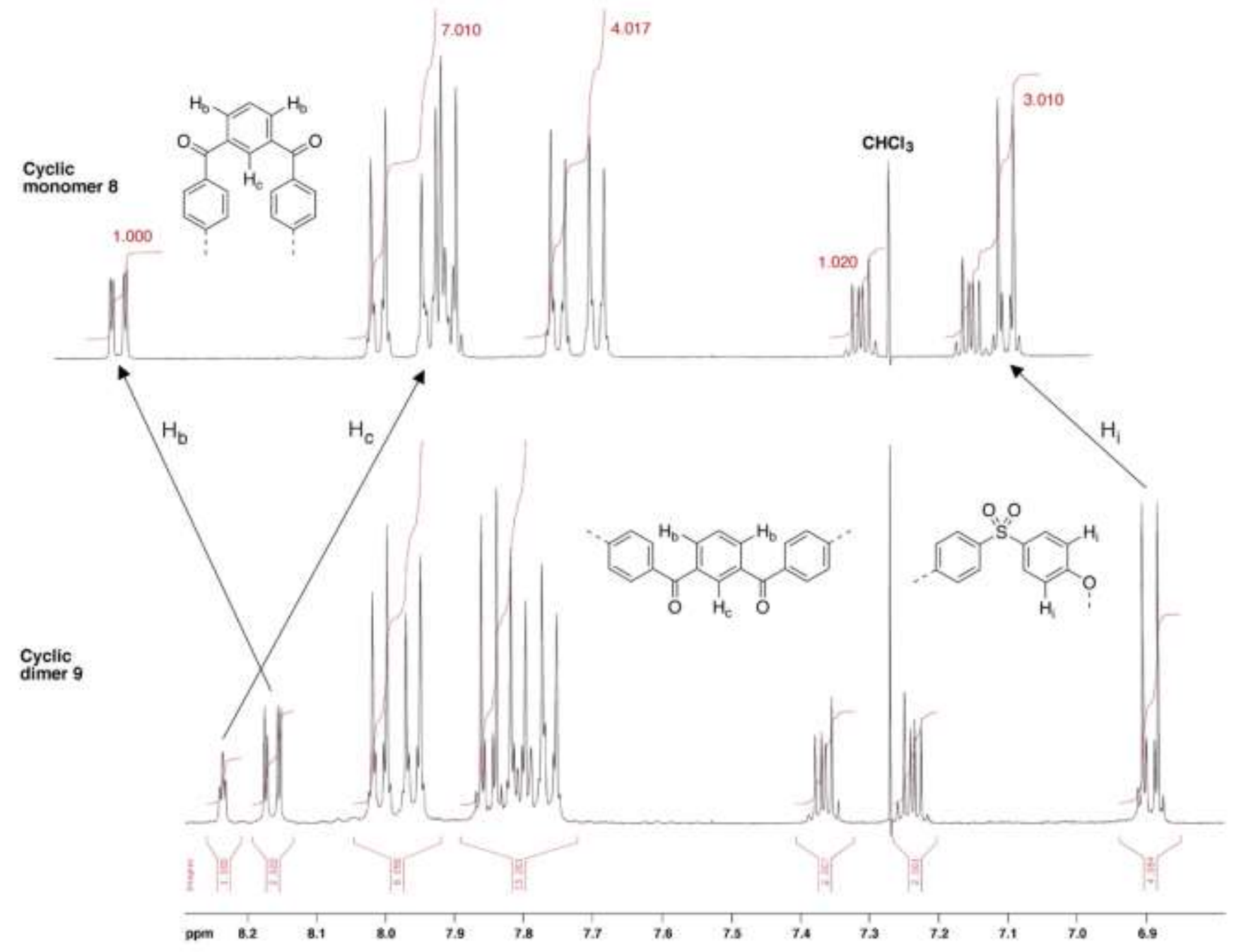

Figure 2. ${ }^{1} \mathrm{H}$ NMR spectra $(400 \mathrm{MHz})$ of cyclic monomer 8 and cyclic dimer $\mathbf{9}$. Integrals are shown in red.

In the ${ }^{1} \mathrm{H}$ NMR spectrum of cyclic monomer 8 , the resonance assigned to the isophthaloyl proton $\mathrm{H}_{\mathrm{c}}$, ortho to both carbonyl groups, (identified by ${ }^{1} \mathrm{H}-{ }^{1} \mathrm{H}$ COSY analysis; see SM) lies at significantly higher field than the resonance for the corresponding protons in cyclic dimer $\mathbf{9}$, the upfield shift being ca. 0.3 ppm (Figure 2). 
This difference is however readily explained in terms of the allowed conformations at the isophthaloyl group. Energy-minimization of computational models for $\mathbf{8}$ and $\mathbf{9}$ (molecular mechanics with charge-equilibration, Cerius2) showed that the diarylisophthaloyl unit in cyclic monomer $\mathbf{8}$ is constrained to adopt a syn conformation in which the proton of interest $\left(\mathrm{H}_{\mathrm{c}}\right)$ is "sandwiched" between two adjacent aromatic rings and is thus subject to significant ring-current shielding (Figure 3).

In contrast, the minimum-energy conformation of cyclic dimer $\mathbf{9}$ is much more open, with the diarylisophthaloyl units adopting an anti conformation in which there can be no intramolecular ring-current shielding of proton $\mathrm{H}_{c}$. Moreover, in this model for cyclic dimer $\mathbf{9}$, it is the isophthaloyl protons $\mathrm{H}_{\mathrm{b}}$, meta to $\mathrm{H}_{\mathrm{c}}$, that now lie in the ring-current shielding zones of the adjacent aromatic rings (Figure 3), accounting for their resonance position upfield (by ca. $0.2 \mathrm{ppm}$ ) relative to the corresponding signal in cyclic monomer 8 (Figure 2). Finally in comparing the ${ }^{1} \mathrm{H}$ NMR spectra of macrocycles 8 and $\mathbf{9}$, the difference in chemical shift of ca. 0.2 ppm, seen for the protons $\mathrm{H}_{\mathrm{i}}$ (Figure 2) may be accounted for in terms of mutual transannular deshielding effects between the adjacent ether-sulfone rings in cyclic monomer 8. Further details of this modelling study, together with atomic coordinates for the final models of macrocycles $\mathbf{8}$ and $\mathbf{9}$, are given in the SM.
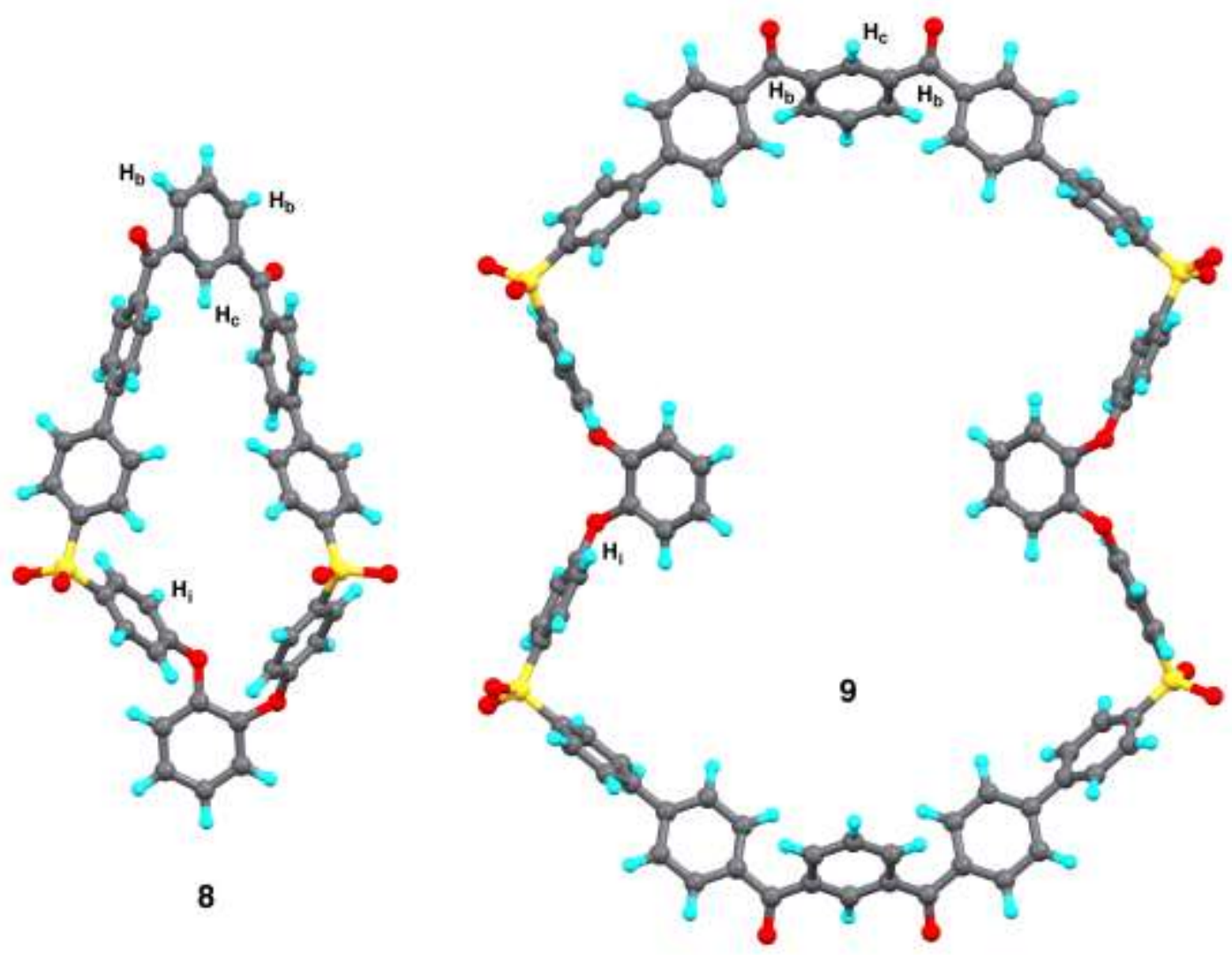

Figure 3. Energy-minimized models for the cyclic monomer $\mathbf{8}$ and cylic dimer $\mathbf{9}$. The isophthaloyl proton $\mathrm{H}_{\mathrm{c}}$ in $\mathbf{8}$ is constrained to lie within the ring-current shielding zones of the two adjacent aromatic rings by the syn conformation of the diarylisophthaloyl unit. Conversely, in 9, the diarylisophthaloyl units can adopt the more open anti conformation, with no ring-current shielding of $\mathrm{H}_{c}$ but now with shielding of the protons $\mathrm{H}_{\mathbf{b}}$. Significant deshielding of the protons $\mathrm{H}_{i}$ is seen in the ${ }^{1} \mathrm{H}$ NMR spectrum of $\mathbf{8}$ relative to $\mathbf{9}$, and this is ascribed to mutual, transannular, ring-current effects between the adjacent "ether-sulfone" rings in cyclic monomer 8. 
Entropy-driven ring-opening polymerization of macrocycle $\mathbf{3}$ was successfully achieved at high temperature $\left(320^{\circ} \mathrm{C}\right)$ in the melt phase, with anhydrous cesium fluoride as catalyst. In this type of process the fluoride ion acts as a nucleophilic initiator, cleaving the activated ether linkage of one macrocycle and generating a free phenoxide end-group which then attacks a second macrocycle, leading to chain-growth polymerization as shown in Scheme 3. The resulting linear polymer $\mathbf{1 0}$ was tough and flexible, and had an inherent viscosity of $0.45 \mathrm{dL} \mathrm{g}^{-1}$, indicative of high $\mathrm{MW}$ and comparable with values for several commercial polyethersulfones including Radel ${ }^{\circledR}$ (also $0.45 \mathrm{dL} \mathrm{g}^{-1}$; see Chart 1 and ref. 7). The new polymer was fully soluble in $96 \%$ sulfuric acid and in mixtures of dichloromethane and trifluoroacetic acid, indicating there was no significant degree of cross-linking between the chains. ${ }^{6}$ In view of the extremely high melting points of 2, 4, 8 and $9\left(>400{ }^{\circ} \mathrm{C}\right)$, and the very low yield of $\mathbf{5}(1.5 \%)$, no comparable polymerizations were possible with these macrocycles.
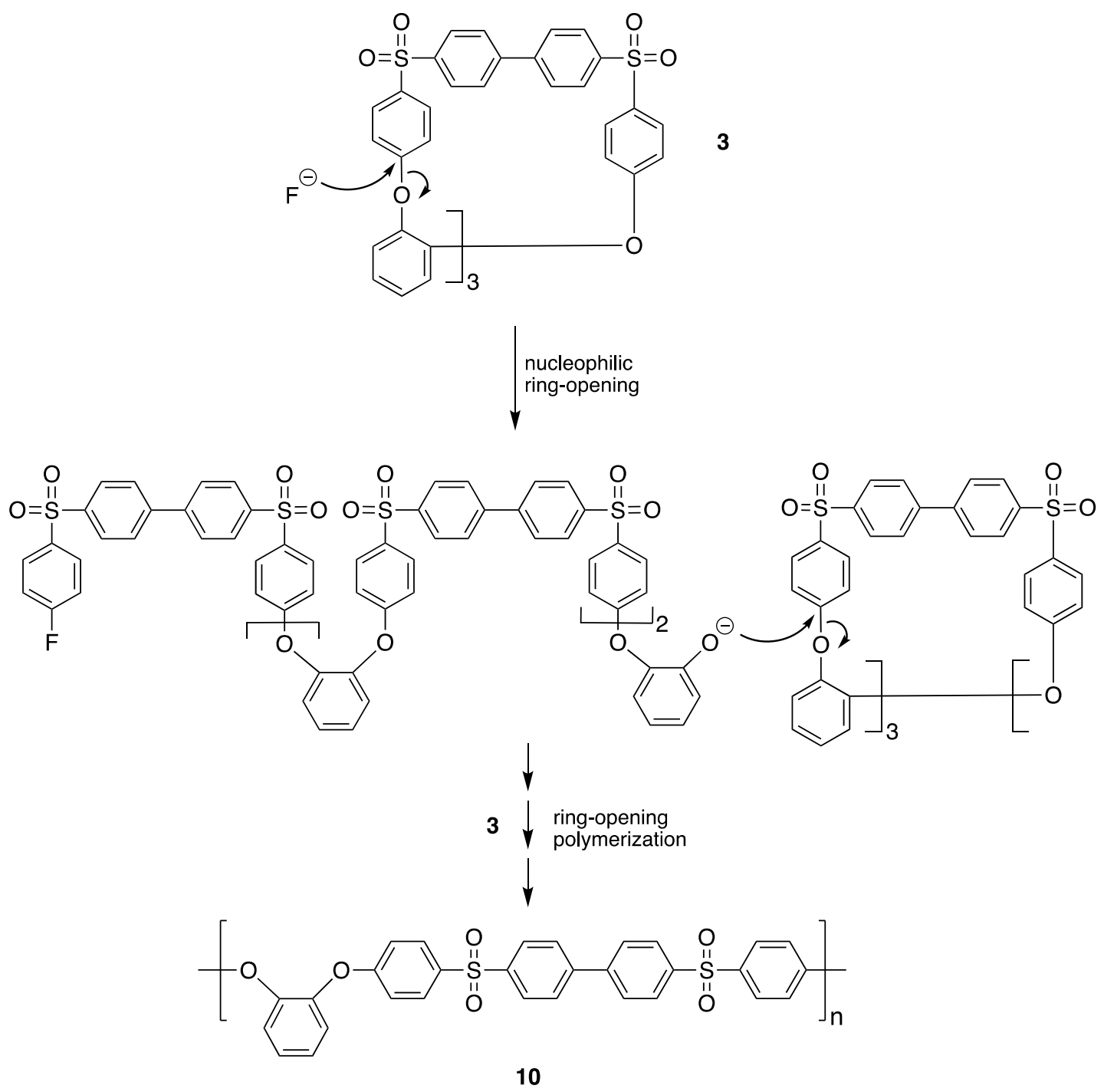

Scheme 3. Nucleophilic ring-opening polymerization of macrocycle $\mathbf{3}$ leading to polymer 10 (note: the fluorophenyl and phenoxide end-groups of $\mathbf{1 0}$ are not shown). 


\section{Conclusions}

This work reports two new families of aromatic ether-sulfone macrocycles. Cyclocondensation under pseudohigh dilution conditions between 4,4'-bis(4"-chlorobenzenesulfonyl)biphenyl and catechol, with subsequent chromatographic separation of the reaction products, led to the isolation of four novel ether-sulfone macrocycles (cyclic dimer, -trimer, -tetramer and -pentamer) that have all been fully characterized. Similarly, reaction between catechol and a novel seven-ring diketone/disulfone monomer allowed the isolation of two new aromatic ether-ketone-sulfone macrocycles, a cyclic monomer and a cyclic dimer, with the cyclic monomer being obtained in unexpectedly high yield (27\%). Interestingly, proton NMR spectrum of the cyclic monomer showed a significant high field resonance-shift of the isophthaloyl proton ortho to both carbonyl groups relative to the corresponding resonance in the cyclic dimer. Potential reasons for this difference were explored by computational modelling, which revealed a constrained syn conformation of the diarylisophthaloyl unit in the cyclic monomer, contrasting with a more open conformation in the cyclic dimer where the diarylisophthaloyl units adopts an anti conformation. As a result, in the cyclic dimer there is no intramolecular ring-current shielding of the corresponding isophthaloyl proton. Finally, given the industrial relevance of poly(ether-sulfone)s, entropy-driven ring-opening polymerization of one of the new macrocycles was studied using a catalytic amount of cesium fluoride as initiator. The resulting poly(ether-sulfone) showed good solubility, indicating an absence of cross-linking, and an inherent viscosity comparable to values for commercially available poly(ether-sulfone)s.

\section{Experimental Section}

General. Starting materials were obtained from Sigma-Aldrich. Potassium carbonate was used after drying under vacuum. Anhydrous aluminum chloride was sublimed under a nitrogen atmosphere before use. $\mathrm{N}, \mathrm{N}$ Dimethylacetamide (DMAc) was distilled from calcium hydride, and catechol was recrystallized from toluene. All other materials were used as received.

NMR data were obtained on Bruker AC250 and JEOL EX400 spectrometers, with chemical shifts recorded in $\delta$ $(\mathrm{ppm})$ and referenced to residual solvent resonances. The abbreviations $\mathrm{s}, \mathrm{d}, \mathrm{dd}, \mathrm{t}, \mathrm{m}$ and br represent singlet, doublet, doublet of doublets, triplet, multiplet and broad respectively. Labelled structures for ${ }^{1} \mathrm{H} N M R$ assignments are given in the SM. Infra-red spectra were obtained from mulls in mineral oil (Nujol) and were recorded on a Perkin-Elmer FT1700 instrument.

Electron ionization mass spectra were run on a VG-BioQ triple quadrupole instrument in positive ion mode. MALDI-TOF mass spectra were obtained on an SAI LT3 Lasertof instrument using 1,8,9-trihydroxyanthracene as matrix. A typical sample preparation was as follows: $0.1 \mathrm{~mL}$ of a solution of the compound in THF (1 $\mathrm{mg} / \mathrm{mL}), 0.1 \mathrm{~mL}$ of a solution of sodium trifluoroacetate in THF $(1 \mathrm{mg} / \mathrm{ml})$ and $0.1 \mathrm{~mL}$ of a solution of the matrix in THF $(20 \mathrm{mg} / \mathrm{ml})$ were combined, and an aliquot of the mixture was then carefully transferred to a sample plate and left to dry in a vacuum oven $\left(40^{\circ} \mathrm{C}\right)$ for 30 minutes prior to the analysis.

Differential scanning calorimetry (DSC) was performed using a Mettler DSC20 system (nitrogen atmosphere, scan rate $10{ }^{\circ} \mathrm{C} / \mathrm{min}$ ). Solution viscosimetry was carried out using a Schott-Gerate CT 150 semi-automated viscometer. The resulting time measurements are applied to the following equation:

$\eta_{\text {inh }}=\ln \left(t_{s} / t_{0}\right) / c$

Where $\eta_{\text {inh }}$ is the inherent viscosity, $\left(t_{\mathrm{s}}\right)$ is the flow time for the polymer solution at concentration $c(\mathrm{~g} / 100 \mathrm{~mL})$, and $t_{0}$ is the flow time for the pure solvent. 
Synthesis of macrocycles 2, 3, 4, and 5. 4,4'-Bis(4"-chlorobenzenesulfonyl)biphenyl (5.00 g, $9.96 \mathrm{mmol}$ ) and catechol (1.10 g, $9.96 \mathrm{mmol})$ were dissolved in DMAc $(120 \mathrm{~mL})$ and the solution was added via a syringe pump under a nitrogen atmosphere, over $48 \mathrm{~h}$, to a vigorously stirred suspension of $\mathrm{K}_{2} \mathrm{CO}_{3}(3.02 \mathrm{~g}, 21.9 \mathrm{mmol})$ in DMAc $(150 \mathrm{~mL})$ and toluene $(80 \mathrm{~mL})$ while the reaction mixture was heated under reflux. At the end of the addition, the mixture was refluxed for a further three hours. The brown solution was then filtered while hot to remove insoluble salts $\left(\mathrm{K}_{2} \mathrm{CO}_{3}, \mathrm{KHCO}_{3}, \mathrm{KCl}\right)$, and distilled water $(300 \mathrm{~mL})$ containing $\mathrm{HCl}(0.5 \mathrm{~mL})$ was then added slowly to the solution. A mixture of homologous cyclic oligomers precipitated as a grey solid which was collected by vacuum filtration and dried in a vacuum oven at $70^{\circ} \mathrm{C}$ overnight.

The cyclic dimer 2 (7.8\%), -trimer 3 (3.4\%), -tetramer 4 (2.0\%), and -pentamer $5(1.5 \%)$ were isolated (in that order) from the product mixture as pure compounds by gradient elution chromatography on silica gel, using dichloromethane/ethylacetate (100/0 to $97 / 3 \mathrm{v} / \mathrm{v})$ as eluent.

The cyclic dimer 2 had $\mathrm{mp} 515^{\circ} \mathrm{C}, \mathrm{m} / \mathrm{z}$ (E/I) [100\%, (M) $\left.{ }^{+}\right]$1080, Calcd. For $\mathrm{C}_{60} \mathrm{H}_{40} \mathrm{~S}_{4} \mathrm{O}_{12}, 1080.1 ;{ }^{1} \mathrm{H} \mathrm{NMR}$ $\left(\mathrm{CD}_{2} \mathrm{Cl}_{2} / \mathrm{CH}_{3} \mathrm{SO}_{3} \mathrm{H}\right.$ 4/1) $\delta(\mathrm{ppm}) 6.78\left(\mathrm{~d}, J 8.9 \mathrm{~Hz}, \mathrm{H}_{\mathrm{d}}\right), 7.22$ and $7.38\left(2 \mathrm{~m}, \mathrm{H}_{\mathrm{e}}\right.$ and $\left.\mathrm{H}_{\mathrm{f}}\right), 7.78\left(\mathrm{~d}, \mathrm{H}_{\mathrm{a}}\right.$ and $\left.\mathrm{H}_{\mathrm{c}}\right), 8.0(\mathrm{~d}, J$ 8.56, $\left.\mathrm{H}_{\mathrm{b}}\right) ;{ }^{13} \mathrm{C}\left(\mathrm{CDCl}_{3} / \mathrm{CF}_{3} \mathrm{COOH}\right) \delta(\mathrm{ppm}) 117.7,123.5,127.9,128.4,128.9,130.1,133.1,140.4,145.1,146.0 ; \mathrm{IR}$ $(\mathrm{KBr}) 3073$ (vCHaromatic), 1576 (C-Caromatic), 1480 and 1157 (vSO $), 1263 \mathrm{~cm}^{-1}$ (vC-O); Anal. Calc. For $\mathrm{C}_{60} \mathrm{H}_{40} \mathrm{~S}_{4} \mathrm{O}_{12}$ : C, 66.65; H, 3.73\%. Found: C, 66.41; H, 3.78\%.

The cyclic trimer 3 showed no melting point and had $\mathrm{m} / \mathrm{z}(\mathrm{E} / \mathrm{I})\left[100 \%,(\mathrm{M})^{+}\right]$1620, Calc. For $\mathrm{C}_{90} \mathrm{H}_{60} \mathrm{~S}_{6} \mathrm{O}_{18}, 1620.2$; ${ }^{1} \mathrm{H} \mathrm{NMR}\left(\mathrm{CD}_{2} \mathrm{Cl}_{2} / \mathrm{CH}_{3} \mathrm{SO}_{3} \mathrm{H}\right.$ 4/1) $\delta(\mathrm{ppm}) 6.87\left(\mathrm{~d}, J 8.99 \mathrm{~Hz}, \mathrm{H}_{\mathrm{d}}\right), 7.26$ and $7.36\left(\mathrm{~m}, \mathrm{H}_{\mathrm{e}}\right.$ and $\left.\mathrm{H}_{\mathrm{f}}\right), 7.78-7.83\left(2 \mathrm{~m}, \mathrm{H}_{\mathrm{a}}\right.$ and $\left.\mathrm{H}_{\mathrm{c}}\right), 7.98\left(\mathrm{~d}, J\right.$ 8.6, $\left.\mathrm{H}_{\mathrm{b}}\right) ;{ }^{13} \mathrm{C}\left(\mathrm{CD}_{2} \mathrm{Cl}_{2} / \mathrm{CH}_{3} \mathrm{SO}_{3} \mathrm{H}\right.$ 4/1) $\delta(\mathrm{ppm}) 117.8,124.2,128.1,128.8,129.4,130.7,134.2$, 141.4, 145.0, 146.3, 162.6; IR ( $\mathrm{KBr}) 3073$ (vCHaromatic), 1581 (vC-Caromatic), 1489 and 1153 (vSO $), 1267 \mathrm{~cm}^{-1}$ (vCO); Anal. Calc. For $\mathrm{C}_{90} \mathrm{H}_{60} \mathrm{~S}_{6} \mathrm{O}_{18}$ : C, 66.65; $\mathrm{H}, 3.73 \%$. Found: $\mathrm{C}, 66.49 ; \mathrm{H}, 3.78 \%$.

The cyclic tetramer 4 had $\mathrm{mp} \quad 424^{\circ} \mathrm{C} ; \mathrm{m} / \mathrm{z}(\mathrm{E} / \mathrm{I})\left[100 \%,(\mathrm{M})^{+}\right] 2160$, Calc. For $\mathrm{C}_{120} \mathrm{H}_{80} \mathrm{~S}_{8} \mathrm{O}_{24}, 2160.3 ;{ }^{1} \mathrm{H} \mathrm{NMR}$ $\left(\mathrm{CD}_{2} \mathrm{Cl}_{2} / \mathrm{CH}_{3} \mathrm{SO}_{3} \mathrm{H}\right.$ 4/1) $\delta(\mathrm{ppm}) 6.88\left(\mathrm{~d}, J 8.94 \mathrm{~Hz}, \mathrm{H}_{\mathrm{d}}\right), 7.22$ and $7.34\left(2 \mathrm{~m}, \mathrm{H}_{\mathrm{e}}\right.$ and $\left.\mathrm{H}_{\mathrm{f}}\right), 7.80\left(\mathrm{t}, \mathrm{H}_{\mathrm{a}}\right.$ and $\left.\mathrm{H}_{\mathrm{c}}\right), 7.99(\mathrm{~d}$, J $\left.8.55 \mathrm{~Hz}, \mathrm{H}_{\mathrm{b}}\right) ;{ }^{13} \mathrm{C}\left(\mathrm{CD}_{2} \mathrm{Cl}_{2} / \mathrm{CH}_{3} \mathrm{SO}_{3} \mathrm{H}\right.$ 4/1) $\delta$ (ppm) 117.8, 124.1, 128.1, 128.8, 129.4, 130.7, 134.3, 141.4, 145.0, 146.4, 162.6; IR ( $\mathrm{KBr}) 3073$ (vCHaromatic) 1576 (vC-Caromatic), 1488, 1152 (vSO 2 ), $1267 \mathrm{~cm}^{-1}$ (vC-O). Anal. Calc. For $\mathrm{C}_{120} \mathrm{H}_{80} \mathrm{~S}_{8} \mathrm{O}_{24}$ : $\mathrm{C}, 66.65 ; \mathrm{H}, 3.73 \%$; Found: $\mathrm{C}, 66.32 ; \mathrm{H}, 3.85 \%$.

The cyclic pentamer 5 showed no melting point and had; $m / z(E / I)\left[100 \%,(M)^{+}\right] 2700$, Calc. For $\mathrm{C}_{150} \mathrm{H}_{100} \mathrm{~S}_{10} \mathrm{O}_{30}$, 2700.3; ${ }^{1} \mathrm{H} N M R\left(\mathrm{CD}_{2} \mathrm{Cl}_{2} / \mathrm{CH}_{3} \mathrm{SO}_{3} \mathrm{H} 4 / 1\right) \delta(\mathrm{ppm}) 6.88\left(\mathrm{~d}, J 8.95 \mathrm{~Hz}, \mathrm{H}_{\mathrm{d}}\right), 7.23$ and $7.33\left(2 \mathrm{~m}, \mathrm{H}_{\mathrm{e}}\right.$ and $\left.\mathrm{H}_{\mathrm{f}}\right), 7.76(\mathrm{~m}$, $\mathrm{H}_{\mathrm{a}}$ and $\left.\mathrm{H}_{\mathrm{c}}\right), 7.97\left(\mathrm{~d}, J 8.56 \mathrm{~Hz}, \mathrm{H}_{\mathrm{b}}\right) ;{ }^{13} \mathrm{C}\left(\mathrm{CD}_{2} \mathrm{Cl}_{2} / \mathrm{CH}_{3} \mathrm{SO}_{3} \mathrm{H}\right.$ 4/1) $\delta(\mathrm{ppm}) 117.9,124.1,128.1,128.8,129.5,130.7$, 134.17, 141.2, 145.0, 146.3, 162.6; IR ( $\mathrm{KBr}) 3074$ (vCHaromatic) 1580 (vC-Caromatic), 1488 and 1153 (vSO $), 1267$ $\mathrm{cm}^{-1}$ (vC-O); Anal. Calc. For $\mathrm{C}_{150} \mathrm{H}_{100} \mathrm{~S}_{10} \mathrm{O}_{30}$ : C, 66.65; H, 3.73\%. Found: C, 66.37; H, 3.80\%.

Synthesis of linear oligomer 7. Isophthaloyl dichloride $(4.00 \mathrm{~g}, 0.0197 \mathrm{~mol}), 4$-(4'-chlorophenylsulphonyl)biphenyl 3.11 (14.24 g, $0.043 \mathrm{~mol})$, and aluminium chloride $(13.08 \mathrm{~g}, 0.043 \mathrm{~mol})$ were heated with stirring in 1,2,4-trichlorobenzene $(35 \mathrm{~mL})$ at $150{ }^{\circ} \mathrm{C}$ for 3 hours, until $\mathrm{HCl}$ evolution virtually ceased. After cooling, the viscous solution was poured into a mixture of water and conc. hydrochloric acid $(250 \mathrm{~mL} / 20 \mathrm{~mL})$. The aqueous phase was separated and the yellow viscous residue was stirred in hexane to solidify the product, which was then extracted twice with methanol $(200 \mathrm{~mL})$ and filtered off The resulting pale yellow powder was dried under vacuum overnight and recrystallized from DMF $(100 \mathrm{~mL})$ to give oligomer 7 as a white powder (6.00 g, 42\%).

Oligomer 7 had $\mathrm{mp} 284^{\circ} \mathrm{C} \mathrm{m} / z$ (E/I) [100\%,(M) $\left.{ }^{+}\right] 786.4$, Calc. For $\mathrm{C}_{44} \mathrm{H}_{28} \mathrm{~S}_{2} \mathrm{O}_{6} \mathrm{Cl}_{2}, 786.1 ;{ }^{1} \mathrm{H}$ NMR $\left(\mathrm{CDCl}_{3} / \mathrm{CF}_{3} \mathrm{COOH}\right.$ 5/1) $\delta(p p m) 7.57\left(\mathrm{~d}, J_{\text {ih }} 8.72 \mathrm{~Hz}, \mathrm{H}_{\mathrm{i}}\right), 7.75-7.85\left(\mathrm{H}_{\mathrm{d}}, \mathrm{H}_{\mathrm{e}}, \mathrm{H}_{\mathrm{a}}\right), 7.93-7.99\left(\mathrm{~m}, \mathrm{H}_{\mathrm{h}}\right.$ and $\left.\mathrm{H}_{\mathrm{f}}\right), 8.07\left(\mathrm{~d}, J_{\mathrm{gh}} 8.5 \mathrm{~Hz}, \mathrm{H}_{\mathrm{g}}\right), 8.14$ and $8.17\left(\mathrm{dd}, J_{\text {ba }} 7.7 \mathrm{~Hz}, \mathrm{H}_{\mathrm{b}}\right), 8.28\left(\mathrm{bs}, \mathrm{H}_{\mathrm{c}}\right) ;{ }^{13} \mathrm{C}\left(\mathrm{CDCl}_{3} / \mathrm{CF}_{3} \mathrm{COOH} 5 / 1\right) \delta(\mathrm{ppm}) 128.2,128.7,129.0,129.4,130.5$, $131.9,135.0,135.4,136.1,137.5,140.0,141.6,144.9,145.7 ; \mathrm{IR}(\mathrm{KBr}) 3052 \mathrm{~cm}^{-1}$ (vCHaromatic), 1647 (vC=O), 1593, (vC-Caromatic), 1475 and 1156 (vSO $), 1107 \mathrm{~cm}^{-1}$ (vCl-Caromatic). 
Synthesis of macrocycles 8 and 9. Potassium carbonate $(0.76 \mathrm{~g}, 5.5 \mathrm{mmol})$, DMAc $(150 \mathrm{~mL})$ and toluene (70 $\mathrm{mL}$ ) were placed in a $500 \mathrm{~cm}^{3}$ three-necked flask equipped with a magnetic stirrer, nitrogen gas inlet and a Dean-Stark trap with condenser and gas outlet. The reaction mixture was then heated until the toluene began to reflux (ca. $160{ }^{\circ} \mathrm{C}$ ). Water was removed by azeotropic distillation with toluene over 2 hours. A solution of compound $7(2.00 \mathrm{~g}, 2.54 \mathrm{mmol})$ and catechol $(0.28 \mathrm{~g}, 2.54 \mathrm{mmol})$ in DMF $(200 \mathrm{~mL})$ was added with a syringe pump at a rate of $10 \mathrm{~cm}^{3}$ per hour. After the end of the addition, the mixture was refluxed overnight. The resulting brown solution was filtered while hot to remove insoluble salts $\left(\mathrm{K}_{2} \mathrm{CO}_{3}, \mathrm{KHCO}, \mathrm{KCl}\right)$. Distilled water $(300 \mathrm{ml})$ containing $\mathrm{HCl}(10 \mathrm{ml})$ was added slowly to the filtered solution until the desired cyclic oligomers precipitated as a brown solid. The mixture of oligomers was collected by vacuum filtration, washed with methanol, filtered again and dried in a vacuum overnight at $70^{\circ} \mathrm{C}$ to give a brown solid.

Gradient elution chromatography with DCM/EtOAc (100/0 to $97 / 3 \mathrm{v} / \mathrm{v})$ on silica gel allowed only two of the macrocyclic oligomers to be isolated as pure compounds, specifically the cyclic monomer $8(27.0 \%)$ and the cyclic dimer 9 (2.0\%).

Cyclic monomer 8 had $\mathrm{mp} 404{ }^{\circ} \mathrm{C}, \mathrm{m} / \mathrm{z}$ (EI) [100\%, (M)+] 823.5, Calc. For $\mathrm{C}_{50} \mathrm{H}_{32} \mathrm{~S}_{2} \mathrm{O}_{8}, 824.1 ;{ }^{1} \mathrm{H} N M R$ $\left(\mathrm{CDCl}_{3} / \mathrm{CF}_{3} \mathrm{COOH} 5 / 1 \mathrm{v} / \mathrm{v}\right), \delta(\mathrm{ppm}) 7.11\left(\mathrm{~d}, J_{\text {ih }} 8.9 \mathrm{~Hz}, \mathrm{H}_{\mathrm{i}}\right), 7.23$ and $7.35\left(\mathrm{~m}, \mathrm{H}_{\mathrm{l}}\right.$ and $\left.\mathrm{H}_{\mathrm{m}}\right)$ 7.66-7.8 $\left(\mathrm{m}, \mathrm{H}_{\mathrm{d}}, \mathrm{H}_{\mathrm{e}}, \mathrm{H}_{\mathrm{a}}\right)$, 7.93-8 (m, $\mathrm{H}_{\mathrm{h}}, \mathrm{H}_{\mathrm{f}}$ and $\left.\mathrm{H}_{\mathrm{c}}\right), 8.07\left(\mathrm{~d}, J_{\mathrm{gh}} 8.6 \mathrm{~Hz}, \mathrm{H}_{\mathrm{g}}\right), 8.38$ and $8.42\left(\mathrm{dd}, J_{\mathrm{ba}} 7.75 \mathrm{~Hz}, J_{\mathrm{bc}} 1.6 \mathrm{~Hz}, \mathrm{H}_{\mathrm{b}}\right) ;{ }^{13} \mathrm{C}$ $\left(\mathrm{CDCl}_{3} / \mathrm{CF}_{3} \mathrm{COOH} 5 / 1 \mathrm{v} / \mathrm{v}\right) \delta(\mathrm{ppm}) 118.5,122.3,127.4,128.0,128.5,130.3,131.7,133.8,135.6,135.9,136.3$, 140.2, 144.7, 145.2, 146.4, 162.3 (C ipso O ether), 199.4 (CO); IR (KBr) 3052 (vCH aromatic), 1654 (vC=O), 1578, (vC-C aromatic), 1487 and 1151 ( $\mathrm{vSO}_{2}$ ), $1222 \mathrm{~cm}^{-1}$ (vC-O); Anal. Calc. For $\mathrm{C}_{50} \mathrm{H}_{32} \mathrm{~S}_{2} \mathrm{O}_{8}: \mathrm{C}, 72.80 ; \mathrm{H}, 3.91 \%$. Found: C, $72.61 ; \mathrm{H}, 3.90 \%$.

Cyclic dimer 9 had $\mathrm{mp} 413{ }^{\circ} \mathrm{C}, \mathrm{m} / \mathrm{z}$ (EI) [100\%, (M) $\left.{ }^{+}\right]$1647.8, Calc. For $\mathrm{C}_{100} \mathrm{H}_{64} \mathrm{~S}_{4} \mathrm{O}_{16}, 1648.3$; ${ }^{1} \mathrm{H} N M R$ $\left(\mathrm{CDCl}_{3} / \mathrm{CF}_{3} \mathrm{COOH} 5 / 1 \mathrm{v} / \mathrm{v}\right), \delta(\mathrm{ppm}) 6.90\left(\mathrm{~d}, \mathrm{~J}_{\mathrm{ih}} 8.93 \mathrm{~Hz}, \mathrm{H}_{\mathrm{i}}\right), 7.28$ and $7.38\left(2 \mathrm{~m}, \mathrm{H}_{\mathrm{l}}\right.$ and $\left.\mathrm{H}_{\mathrm{m}}\right) 7.75-7.87\left(\mathrm{H}_{\mathrm{d}}, \mathrm{H}_{\mathrm{e}}, \mathrm{H}_{\mathrm{g}}\right.$ and $\left.\mathrm{H}_{\mathrm{a}}\right), 7.95-8.03\left(\mathrm{~m}, \mathrm{H}_{\mathrm{h}}, \mathrm{H}_{\mathrm{f}}\right), 8.16$ and $8.18\left(\mathrm{dd}, \mathrm{J}_{\mathrm{ba}} 7.78 \mathrm{~Hz}, \mathrm{H}_{\mathrm{b}}\right), 8.28\left(\mathrm{bs}, \mathrm{H}_{\mathrm{c}}\right) ;{ }^{13} \mathrm{C}\left(\mathrm{CDCl}_{3} / \mathrm{CF}_{3} \mathrm{COOH} 5 / 1\right) \delta$ (ppm) 117.44, 123.77, 127.78, 128.21, 128.36, 128.93, 130.21, 131.92, 133.32, 135.97, 137.31, 140.34, 145.08, 145.45, 145.99, 162.53 (C ipso O ether), 199.5 (CO); IR (KBr) 2920 (vCHaromatic), 1656 (vC=O), 1593, (vC-Caromatic), 1487 and 1152 (vSO 2$), 1265 \mathrm{~cm}^{-1}$ (vC-O).

Ring-opening polymerization of macrocycle 3. Polymerization of $\mathbf{3}$ was carried out in an aluminium DSC pan. The macrocycle was ground with 3 mol\% of anhydrous cesium fluoride and a pelletized $20 \mathrm{mg}$ sample of the mixture was heated at $320^{\circ} \mathrm{C}$ for 1 hour under nitrogen in the DSC instrument and then cooled to room temperature. A subsequent DSC scan to $400{ }^{\circ} \mathrm{C}$ showed the resulting polymer to be amorphous (no melting transition) and to have a glass transition temperature $\left(\mathrm{T}_{\mathrm{g}}\right)$ of $207^{\circ} \mathrm{C}$. On cooling, the polymer was recovered in the form of a tough, yellow, transparent pellet that dissolved completely in $96 \%$ sulfuric acid, in which solvent it showed an inherent viscosity $\left(\eta_{\text {inh }}\right)$ of $0.46 \mathrm{dL} \mathrm{g}^{-1}$.

\section{Acknowledgements}

We wish to thank the University of Reading for support (PhD studentship to F. Aricò), and Professor Philip Hodge of the University of Manchester for valuable discussions.

\section{Supplementary Material}

Spectroscopic data $\left({ }^{1} \mathrm{H}\right.$ NMR, ${ }^{13} \mathrm{C}$ NMR, MALDI-TOF MS) for all products can be found in the supplementary material file, together with details of the computational modelling study. Atomic coordinates for the final models are available from the authors as electronic files in pdb format. 


\section{References}

1. Fink, J. High Performance Polymers, 2nd Edn.; William Andrew: New York, 2014. https://doi.org/10.1016/B978-0-323-31222-6.00009-1

2. Mittal, V. in High Performance Polymers and Engineering Plastics; Mittal, V. Ed.; Scrivener: Salem, 2011; pp 1-20. https://doi.org/10.1002/9781118171950

3. Cudby, M. E. A.; Feasey, R. G.; Gaskin, S.; Jones, M. E. B.; Rose, J. B. J. Polym. Sci., Polym. Symp. 1967, 22, 747-760.

https://doi.org/10.1002/polc.5070220217

4. Attwood, T. E.; Barr, D. A.; King, T.; Newton, A. B.; Rose, J. B. Polymer 1977, 18, 359-364. https://doi.org/10.1016/0032-3861(77)90083-0

5. Clendinning, R. A.; Farnham, A. G.; Johnson, R. N. In High Performance Polymers: Their Origin and Development; Seymour, R. B.; Kirshenbaum, G. S., Eds.; Elsevier: New York, 1986; pp 149-158. https://doi.org/10.1007/978-94-011-7073-4 15

6. Rose, J. B. in High Performance Polymers: Their Origin and Development; Seymour, R. B.; Kirshenbaum, G. S., Eds.; Elsevier: New York, 1986; pp 169-185.

7. Colquhoun, H. M.; Lewis, D. F.; Hodge, P.; Ben-Haida, A.; Williams, D. J.; Baxter, I. Macromolecules 2002, 35, 6875-6882. https://doi.org/10.1021/ma020315u

8. Ben-Haida, A.; Hodge, P.; Nisar, M.; Helliwell, M. Polym. Adv. Technol. 2006, 17, 682-690. https://doi.org/10.1002/pat.726

9. Brydia, L. E.; Garty, O. M. J. Polym. Sci., Polym. Chem. Ed. 1980, 18, 1577-1586. https://doi.org/10.1002/pol.1980.170180515

10. Colquhoun, H. M.; Williams, D. J. Macromolecules 1996, 29, 3311-3314. https://doi.org/10.1021/ma951628a

11. Savariar, S.; Underwood, G. S.; Dickinson, E. M.; Schielke, P. J.; Hay, A. S. Desalination 2002, 144, 15-20. https://doi.org/10.1016/S0011-9164(02)00282-5

12. Baxter, I.; Colquhoun, H. M.; Hodge, P.; Kohnke, F. H.; Lewis, D. F.; Williams, D. J. J. Mater. Chem. 2000, 10, 309-314.

https://doi.org/10.1039/a908414b

13. Brunelle, D. J.; Bradt, J. E.; Serth-Guzzo, J.; Takekoshi, T.; Evans, T. L.; Pearce, E. J., Wilson, P. R. Macromolecules 1998, 31, 4782-4790. https://doi.org/10.1021/ma971491j

14. Ding, Y.; Hay, A. S.; Macromolecules 1996, 29, 6386-6392. https://doi.org/10.1021/ma9605006

15. Colquhoun, H. M.; Aricò F.; Williams, D. J. Chem. Commun. 2001, 2574-2575. https://doi.org/10.1039/b108124c

16. Colquhoun, H. M.; Aricò F.; Williams, D. J. New J. Chem. 2002, 26, 1703-1705. https://doi.org/10.1039/B208002H

17. Baxter, I.; Ben-Haida, A.; Colquhoun, H. M.; Hodge, P.; Kohnke, F. H.; Williams, D. J. Chem. Commun. 1998, 2213-2214.

https://doi.org/10.1039/a805556d

18. Ben-Haida, A.; Hodge, P.; Colquhoun, H. M. Macromolecules 2005, 38, 722-729. 
https://doi.org/10.1021/ma0401370

19. Jacobson, H.; Stockmayer, W. H. J. Chem. Phys. 1950, 18, 1600-1606.

https://doi.org/10.1063/1.1747547

20. Semlyen, J. A. Adv. Polym. Sci. 1976, 21, 41-75.

21. Ercolani, G.; Mandolini, L.; Mencareli, P.; Roelens, S. J. Am. Chem. Soc. 1993, 115, 3901-3908.

https://doi.org/10.1021/ja00063a008

22. Hodge, P. Chem. Rev. 2014, 114, 2278-2312.

https://doi.org/10.1021/cr400222p

23. Hodge P. Polym. Adv. Technol. 2015, 26, 797-803.

https://doi.org/10.1002/pat.3469

24. Youk, J. H.; Kambour, R. P.; MacKnight, W. J. Macromolecules 2000, 33, 3594-3599. https://doi.org/10.1021/ma991838d

25. Coates, G. W.; Getzler, Y. D. Y. L. Nat. Mater. Rev. 2020, 501-516. https://doi.org/10.1038/s41578-020-0190-4

26. Colquhoun, H. M.; Lewis, D. F.; Ben-Haida, A.; Hodge, P. Macromolecules 2003, 36, 3775-3778. https://doi.org/10.1021/ma0215969

27. Morgan, P. W. Macromolecules 1977, 10, 1381-1390. https://doi.org/10.1021/ma60060a040

28. Ben-Haida, A.; Colquhoun, H. M.; Hodge, P.; Williams D. J. Macromolecules 2006, 39, 6467-6742. https://doi.org/10.1021/ma060885k

29. Masasi. J.; Dao, B.N.; Dell’Olio, C.; Swan S. R.; Issadazeh, S.; Wiggins, J. S.; Varley, R. J.; Compos. Sci. Technol. 2021, 201, 108534. https://doi.org/10.1016/i.compscitech.2020.108534

30. Shaikh, A. A.; Schwarz, G.; Kricheldorf, H. R. Polymer 2003, 44 , 2221-2230. https://doi.org/10.1016/S0032-3861(02)00910-2

31. Wang, C.; Kelley, S. S.; Venditti, R. A. ChemSusChem 2016, 9, 770 - 783. https://doi.org/10.1002/cssc.201501531

32. Ben-Haida, A.; Colquhoun, H. M.; Hodge, P.; Raftery, J.; White, A. J. P.; Williams, D. J., Org. Biomol. Chem. 2009, 7, 5229-5235.

https://doi.org/10.1039/b912193e 